\title{
EL DERECHO A LA DEMOCRACIA EN LAS AMERICAS
}

\author{
Heraldo Muñoz $V$.
}

En el sistema interamericano ha existido históricamente la tendencia a entender la democracia como una obligación jurídica. Considerando que el "derecho a la democracia" se ha transformado en un imperativo normativo y se está implementando mediante la acción colectiva pacífica, el autor plantea que la OEA tiene que cumplir el rol de buscar una convergencia entre doctrina y acción concreta. Primeramente, se explica cómo ha evolucionado la doctrina y la práctica de la democracia en el sistema interamericano, señalando los prịncipales hitos en este sentido. Luego, se hace referencia a algunas iniciativas recientes de la organización con respecto a la democracia -los casos de Haití, Perú y Guatemala, así como la supervisión de eleciones en varios países- y la revisión del concepto tradicional de soberanía. Como conclusión se reafirma èl argumento inicial de que se está consolidando un "derecho a la democracia" en el sistema interamericano.

\section{Introducción.}

En su perceptivo libro, On the Law of Nations, Daniel Patrick Moynihan afirma que el derecho internacional "no es un derecho superior o el mejor; es la ley que existe. No es un derecho que evita fuerza; tal perspectiva es ajena a la misma idea del derecho. Con frecuencia es el derecho del vencedor; pero, con todo, es la ley y siempre evoluciona": ${ }^{1}$

Esta interpretàción dinámica del derecho internacional es particularmente adecuada para comprender la importancia creciente de la democracia como un derecho global y como un sine qua non "para validar la gobernabilidad" ${ }^{2}$ especialmente en el sistema interameri-

\footnotetext{
${ }^{1}$ Daniel Patrick Moynihan, On the Law of Nations, (Cambridge, Mass.: Harvard University Press, 1990), p. 19.

${ }^{2}$ Ver el importante artículo de Thomas M. Franck, "The Emerging Right to Democratic Governance ${ }^{n}$, American Joumal of International Law, Vol. 85, N11, enero de 1992, pp. 65-66.
} 
cano. En un contexto de post-Guerra Fría de predominio a nivel mundial de los mercados y las elecciones libres, los países del hemisferio occidental han estado en la vanguardia de la acción colectiva en favor de la democracia. Un avance histórico en la reafirmación.y defensa de la democracia aconteció cuando los Ministros de Relaciones Exteriores de las Américas, durante la Asamblea General de la Organización de Estados Americanos (OEA) de junio 1991, firmaron el "Compromiso de Santiago con la Democracia y la Renovación del Sistema Interamericano" y adoptaron la resolución "Democracia Representativa" (resolución 1080), ${ }^{3}$ que creó un mecanismo para responder de manera automática a una interrupción ilegal del proceso democrático en cualquier país de la región, permitiendo así que la Organización actuara oportunamente en los casos de Haití, Perú y Guatemala.

Estos pronunciamientos de la OEA en efecto constituyeron un importante paso hacia la transformación de la democracia de una prescripción moral a una obligación jurídica internacional. A la vez, fueron posibles gracias al fin de la Guerra Fría, porque el término de ese conflicto disminuyó en forma drástica el riesgo de que resoluciones que aprueban una acción hemisférica en favor de la democracia fuesen consideradas como autorizaciones para fines políticos vagamente vinculados, o desvinculados del todo, con la consolidación y preservación de la democracia representativa. En los últimos años ha existido, además, particularmente entre los países latinoamericanos, un deseo compartido de salvaguardar y consolidar las democracias recientemente recuperadas ante la amenaza del autoritarianismo y sus secuelas después de un largo período de dictadura.

Pero, si bien el Compromiso de Santiago y la resolución sobre democracia representativa son dos hitos en la protección efectiva de la democracia en las Américas, ellos son las expresiones más recientes de una tendencia de larga data hacia la afirmación de los propósitos y principios democráticos contenidos en la Carta de la OEA y en innumerables declaraciones, resoluciones y medidas adoptadas por la organización hemisférica. En efecto, las Américas son una región donde la democracia y la protección de los derechos humanos se han desarrollado mucho más allá que otras regiones, tanto como una obligación jurídica, política y moral.

\footnotetext{
${ }^{3}$ Ver Resolución 1080, "Democracia Representativa", $x \times 1$ Asamblea General de OEA, junio 1991, Santiago, Chile.
} 
En esta línea, este artículo argumenta que ahora existe un "derecho a la democracia" en el derecho internacional americano, en el sentido que una doctrina ya existente sobre la defensa y promoción de la democracia en el sistema interamericano ahora se ha transformađ̣o en una obligación normativa y, más importante aún, que dicho derecho a.la democracia se está implementando mediante la acción colectiva pacífica. Este derecho a la democracia no se debe entender como la aceptación creciente por la comunidad internacional de un "derecho nuevo" - debido a que numerosos acuerdos hemisféricos y. mundiales han establecido claramente los derechos básicos, civiles y políticos, que constituyen la esencia de la democracia representativa-sino, más bien, como el reconocimiento creciente en las Américas de que la democracia puede y debe ser defendida mediante acciones colectivas de carácter pacífico.

La creciente aceptación de un derecho a la democracia en el derecho internacional americano ha puesto en duda la noción clásica de que la legitimidad política interna en un determinado país es, esencialmente, un tema que corresponde a la jurisdicción exclusiva del Estado y, por tanto, está exenta incluso de una "intervención blanda por parte de organizaciones internacionales o de la comunidad internacional en su conjunto". ${ }^{4}$ La soberanía tradicional ha sido desafiada no solamente por el reconocimiento de que la comunidad internacional puede y debe insistir en el derecho a un gobierno democrático, sino también por una profundización de la interdependencia económica global y de los cambios tecnológicos que están moldeando un mundo donde, por ejemplo, las ideas, los capitales, la. información y las imágenes se saltan las fronteras políticas y geográficas cada vez con mayor rapidez y facilidad.

Cabe hacer notar, sin embargo, que en el sistema interamericano con bastante frecuencia la teoría no ha equiparado a la práctica en relación a la democracia. La sólida doctrina hemisférica sobre gobernabilidad democrática a menudo no fue llevada a la práctica debido a la intervención de motivaciones de política de poder relacionadas con los intereses de los Estados Unidos y, en algunos casos, con los intereses de los propios países latinoamericanos.

En un momento cuando la idea democrática ha ganado legitimidad a través del mundo, muchos gobiernos y actores privados asignan una gran importancia a la búsqueda por parte de la OEA -la

\footnotetext{
${ }^{4}$ Fernando R. Teson, "Changing Perceptions of Domestic Jurisdiction and Intervention", mimeo, Inter-American Dialogue Seminar, Washington, D.C., marzo 1993, p. 17.
} 
organización política principal del sistema interamericano- de una convergencia entre doctrina y acción concreta sobre tan relevante materia. En el último término, la OEA será evaluada principalmente por su grado de compromiso y capacidad para actuar efectivamente en conformidad con su compromiso doctrinario con la promoción y defensa de democracia en las Américas. En todo caso, se puede afirmar con cierta seguridad que ya se han establecido las bases normativas del derecho a la democracia en las Américas.

\section{La evolución de la doctrina de la democracia en el sistema interamericano y su práctica.}

El camino hacia el reconocimiento de la democracia como el principio orientador de los Estados americanos ha sido largo y constante, comenzando como compromiso moral hasta transformarse en una norma vinculante establecida en la Carta de la OEA. El gobierno democrático ha sido una meta consistente de los pueblos de las Américas casi desde los tiempos de la independencia y el desplome de las monarquías absolutas como formas de gobierno. Las medidas actuales emprendidas por el OEA en nombre de la democracia tienen, por tanto, una historia extensa, aunque irregular o inconsistente.

La Conferencia de Washington de 1907 formalizó el principio de la democracia en la región centroamericana. En el Tratado General de Pazy la Amistad resultante de esa conferencia, las repúblicas del istmo acordaron, entre otros puntos, el no-reconocimiento de los gobiernos centroamericanos que surgieran de rebeliones en vez de elecciones libres. En otra conferencia, en 1922-1923, los países centroamericanos reafirmaron los acuerdos de 1907 y fueron más allá al prohibir el reconocimiento de gobiernos instalados por el uso de la fuerza, aun cuando fuesen consagrados más tarde por medio de elecciones libres. En esa época, Estados Unidos mantenía una política activista de fomento de la democracia en la región -particularmente en Centroaméríca y el Caribe- que duró hasta la administración de Herbert Hoover. ${ }^{5}$ Aparentemente, la Gran Depresión detuvo la campaña en favor de la democracia en las Américas.

\footnotetext{
5Ver Paul W. Drake, "From Good Men to Good Neighbors, 1912-1932", en: Abraham Lowenthal (ed.); Exporting Democracy: The United States and Latin America, (Baltimore: The Johns Hopkins University Press, 1991). Drake nos recuerda que durante 1914-1916, el Presidente Woodrow Wilson incluso buscó, sin éxito, la aprobación de un Pacto Panamericano de Libertad para apoyar los gobiernos republicanos en el hemisferio.
} 
Dentro del sistema interamericano propiamente tal, el primer pronunciamiento oficial de la "existencia de la democracia como una causa común en América" se encuentra en la "Declaración de Principios sobre Solidaridad Interamericana y Cooperación" de la Conferencia Interamericana sobre la Consolidación de Paz, celebrada en Buenos Aires en 1936. Entre 1936 y 1945, cada conferencia interamericana que siguió reiteró esa declaración en algún aspecto de su quehacer.

El21 de noviembre de 1945, el entonces Ministro de Relaciones Exteriores de Uruguay, Dr. Eduardo Rodríguez Larreta, dirigió una nota a los gobiernos americanos en que propuso una acción multilateral para defender la democracia y los derechos humanos. Su propuesta -endosada con entusiasmo por el Secretario de Estado de Estados Unidos, James F. Byrnes- enfatizó el paralelo entre la defensa de la libertad humana y la mantención de lä páz, y sostuvo el punto de vista de que los Estados de la región déberían actuar en conjunto para asegurar la democracia, sin llegar a violar el principio de la no-intervención. Dicha propuesta no fue aprobada, pero ya era indicativa del continuo interés hemisférico sobre la defensa de la democracia.

De conformidad con la tesis principal de este trabajo que los países de la región han exigido más de sí mismos en materia de democracia y derechos humanos que países de otros continentes -incluso en un momento cuando dichos conceptos no disfrutaban de la aceptación internacional que hoy en día tienen-, la historia demuestra que las naciones del hemisferio occidental trabajaron arduamente en San Francisco para introducir el tema de derechos humanos en la Carta de las Naciones Unidas. Los países americanos, además, demostraron liderazgo internacional en la materia cuando adoptaron la Declaración Americana de Derechos Humanos, en 1948, siete meses antes de la firma de la Declaración Universal de los Derechos del Hombre de Naciones Unidas.

La Conferencia Interamericana sobre los Problemas de la Guerra y la Paz, celebrada en Ciudad de México en 1945, produjo un documento conocido como la Declaración de México que mantuvo como un principio esencial de la comunidad hemisférica que "el hombre americano no puede concebir la vida sin justicia" ni puede concebir "la vida sin libertad." Otra resolución, titulada "Preservación y Defensa de Democracia en América", encomendó al Comité Jurídico Interamericano la consideración de un anteproyecto sometido 
por Guatemala en oposición a la eventual instalación de regîmenes antidemocráticos jen la región y la presentación de un infórime al respecto a la Novena Conferencia Americana Internacional, la histórica Conferencia de Bogotá celebrada en 1948.

La Conferencia de Bogotá adoptó una resolución en que los Estados americanos reafirmaron "su convicción de que se puede lograr la meta de desarrollo social y económico efectivo solamente en un sistema fundado sobre la garantía de los derechos y libertades esenciales del individuo". Además; condenó "los métodos de todo sistema que tienda a suprimir derechos y libertades políticas y civiles...". La Conferencia culminó con la firma de la Carta de la OEA de la Declaración Americana de Derechos Humanos: mencionada anteriormente, representando con ello un avance đesdélas déclaraciones en nombre de la democracia a normas éspécificás dé una naturaleza vinculante. Como afirmó el ex-Presidente de Colombia, Alberto Lleras, en referencia a los principios de Carta, al entrar ésta en vigencia tales principios derivaron en "normas de una naturaleza indiscutiblemente obligatoria, si bien ellos siempre tuvieron una fuerza moral inequívoca en las resoluciones y declaraciones que precedieron la Carta".

La Carta de Bogotá es bastante clara. Su preámbulo dice que "el verdadero significado de la solidaridad americana y de la buena vecindad no puede ser otro que el de consolidar en este continente, dentro del marco de las instituciones democráticas, un sistema de libertad individual y justicia social, fundado en el respeto de los derechos esenciales del hombre", y más adelante establece en el Capítulo II, Principios, que "la solidaridad de los Estados americanos y los altos fines que con ella se persiguen requieren la organización política de los mismos sobre la base del ejercicio efectivo de democracia representativa".

Evidentemente, una vez que la "solidaridad democrática" adquirió un carácter convencional con la firma y ratificación de la Carta, cualquier golpe o interrupción ilegal de los procesos democráticos en efecto socava la solidaridad de los países hemisféricos y plantea un claro desafío a uno de los propósitos esenciales de la Organización de Estados Americanos. Además, en base al artículo precitado de la Carta original, ya se podía argumentar en ese entonces que la pre-

\footnotetext{
${ }^{6}$ Ver Resolución XXXII del Noveno Conferencia Americana International, Bogotá, Colombia, 1948.
} 
sencia en la organización de Estados con gobiernos no-democráticos es incompatible con los fines perseguidos por la organización americana.

Es interesante destacar que, en la Conferencia de Bogotá que dio origen a la OEA, Brasil propuso que el ingreso de un Estado miembro en la organización estuviese sujeto a la ratificación de la Carta y a la adopción de una forma democrática de gobierno y a la garantía de los derechos fundamentales del hombre. Ese mismo año, cuando la Carta de la OEA estaba bajo discusión, Perú propuso que cuando surgiese un "gobierno de facto", "los gobiernos intercambien puntos de vista sobre si es necesario reconocerlo o no y el momento en que se debe hacer...".

Después de la Conferencia de Bogotá, con la aparición de gobiernos dictatoriales en América Latina, el desarrollo de pronunciamientos interamericanos adicionales para promover la democracia representativa disminuyó notoriamente. Entre fines de 1948 y mediados de 1954, una media docena de regímenes democráticos fueron derrocados y reemplazados por dictaduras militares. Los esfuerzos orientados a revertir la tendencia dictatorial no prosperaron, incluyendo aquellos de la famosa "Legión Caribeña" de líderes exiliados que, durante 1947-1949, intentaron acciones colectivas en apoyo a la democracia en el Caribe y Centroamérica. ${ }^{7}$ No obstante, diversas reuniones y conferencias interamericanas reafirmaron, al menos en teoría, el compromiso hemisférico con la democracia representativa y la solidaridad democrática en las Américas.

Una década después de Bogotá, la Quinta Reunión de Consulta de los Ministros de Relaciones Exteriores, celebrada en Santiago, Chile, en agosto 1959, marcó otro hito en el desarrollo de lo que aquí se denomina la doctrina interamericana de la democracia. De esa reunión surgió una lista parcial de atributos específicos de una democracia representativa, se creó la Comisión Interamericana de Derechos Humanos, y el Comité Jurídico Interamericano fue encomendado con la redacción de una convención sobre derechos humanos que consideraría la relación legal entre el respeto por los derechos humanos y el ejercicio efectivo de democracia representativa. También se pidió al Comité que redactara un anteproyecto

\footnotetext{
${ }^{7}$ Según el historiador Leslie Bethell, los Estados Unidos "se opusieron inequívocamente" a los esfuerzos de la Legión Caribeña auspiciados por José Figueres, Ramón Grau San Martín, Rómulo Betancourt y Juan Arévalo. Ver L. Bethell, "From the Second World War to the Cold War 1944-1954", en: Abraham Lowenthal (ed.), op. cit, p. 63.
} 
de una Convención sobre el "Ejercicio Efectivo de Democracia Representativa". Además, la Quinta Reunión de Consulta aseveró inequívocamente en la "Declaración de Santiago" que: "La existencia de regímenes antidemocráticos constituye una violación de los principios sobre los cuales se funda la Organización de Estados Americanos y un peligro para las relaciones de paz y unidad en el hemisferio."

De 1959 en adelante, hubo una intensa discusión dirigida a aclarar el alcance del compromiso democrático de la organización hemisférica. El informe del Comité Jurídico Interamericano reafirmó la interrelación entre derechos humanos y el ejercicio de la democracia y respaldó la naturaleza obligatoria de los principios de la Carta; pero, en su informe aprobado por mayoría, la acción colectiva en defensa de la democracia, o para restaurarla, fue considerada como inadmisible bajo los términos de la Carta de Bogotá. Se determinó, por tanto, que el Proyecto de Convención sobre el Ejercicio Efectivo de Democracia Representativa resultaba demasiado controvertido para esa época.

A pesar de la Guerra Fría, del impacto de la revolución cubaná, y de la preponderancia de regímenes dictatoriales durante las décádas de los sesenta y los setenta, varias reuniones interamericanas continuaron reafirmando, al menos en teoría, los conceptos de libertad y democracia representativa establecidos en la Carta.

Quizás uno de los episodios más tempranos pero menos conocidos de la preocupación de los Estados miembros de la OEA con la adópción de pasos específicos en la organizàción para preservar la democracia y prevenir los golpes de Estado, sucedió en agosto de 1962. En ese momento transcurrieron varias reuniones especiales del Consejo Permanente para considerar un pedido de los gobiernos de la República Dominicana, Venezuela, Honduras y Costa Rica para convocar a una Reunión de Consulta de Ministros de Relaciones Exteriores para "reafirmar la solidaridad democrática en América y para considerar qué actitud deberían adoptar los gobiernos de los Estados miembros frente a regímenes surgidos de golpes de Estado". El pedido para convocar una Reunión de Consulta, alimentado por una preocupación acerca de un posible golpe en Perú, provocó una discusión sustantiva y una votación posterior en que no se alcanzó a conseguir la mayoría necesaria para la aprobación del pedido.

La existencia de un número considerable de gobiernos dictatoriales en la región, así como también la intensificación del conflicto 
Este-Oeste, frustró ese temprano intento de discutir maneras específicas para implementar el principio de la solidaridad americana con el ejercicio efectivo de la democracia representativa. Es interesante señalar que Estados Unidos adoptó una posición cautelosa y no se unió al esfuerzo encabezado por Venezuela y Costa Rica de solicitar la Reunión de Consulta. Aparentemente, el voto de abstención de Washington reflejó un deseo de no perturbar la coalición regional de gobiernos de facto anticomunistas.

En noviembre de 1963, el Consejo Permanente de la OEA adoptó una resolución que convocaba a una Reunión de Consulta de Cancilleres sobre democracia representativa. Pero, más tarde se decidió que dicha temática debía examinarse en una conferencia interamericana. Por lo tanto, la convocatoria a la reunión se canceló, y los temas que involucraban el fortalecimiento de la democracia fueron transferidos a la agenda de la Segunda Conferencia Interamericana Extraordinaria, celebrada en Río de Janeiro en novịembre 1965. La reunión de Río adoptó una resolución interesante titulada "Procedimiento Informal sobre el Reconocimiento de Gobiernos De Facto", en que se recomendó que los Estados miembros, inmediatamente después del derrocamiento de un gobierno legítimo, iniciasen intercambios entre ellos sobre la situación. Teniendo presente la voluntad del gobierno de facto para realizar elecciones libres dentro de un período razonable y su compromiso a cumplir con sus obligaciones internacionales anteriores, una vez ocurridas las consultas, se recomendó que "cada gobierno decidirá si mantendrá relaciones diplomáticas con el gobierno de facto." A pesar de su debilidad sustantiva, la resolución reflejó la persistente preocupación sobre cómo enfrentar a los regímenes antidemocráticos desde una posición multilateral.

En el ámbito de la acción concreta y en nombre de democracia, aunque el motivo formal fue el de rechazar la agresión a Venezuela por parte del gobierno de la República Dominicana encabezado por Leonidas Trujillo, el Consejo Permanente de la OEA, reunido como un órgano de consulta bajo el TIAR (Tratado Interamericano de Asistencia Recíproca), decidió en julio de 1960 romper relaciones diplomáticas con la República Dominicana y cortar parcialmente los vínculos económicos de los Estados miembros con esa nación. Trujillo se había transformado en un adversario de la democracia en la Cuenca del Caribe, al punto de promover actos subversivos para derrocar al gobierno venezolano. En parte como resultado de las 
sanciones, la OEA contribuyó a debilitar al gobierno autoritario dominicano y, como resultado, hizo concordar los principios establecidos en la Carta con la práctica interamericana sobre democracia.

En el caso de Cuba -en el punto máximo de la Guerra Fría-, una Reunión de Cancilleres, en julio 1964, actuando dentro del marco del TIAR, condenó al régimen de Fidel Castro por intento de derrocar al gobierno democrático de Venezuela y llamó a la suspensión de relaciones diplomáticas así como de los vínculos económicos y de transporte con la isla caribeña. Dos años antes, en Punta del Este, Uruguay, la OEA, nuevamente amparada por el Tratado de Río y recordando el principio de la democracia representativa y la Declaración de Santiago sobre elecciones libres como la piedra angular de los gobiernos americanos, había expulsado por un voto de mayoría al gobierno de Cuba del sistema interamericano, consignando, adicionalmente, que el gobierno cubano marxista-leninista era "incompatible con los principios y los objetivos del sistema interamericano". La Guerra Fría estaba dando un giro Este-Oeste a la promoción del ideal democrático.

En mayo 1965, la crisis dominicana sacudió el sistema interamericano. Otra Reunión de Cancilleres -esta vez fuera del marco del TIAR-, resolvió transformar la acción armada unilateral de Estados Unidos en la República Dominicana en una operación colectiva al convertir a las fuerzas militares extranjeras en territorio dominicano en una "fuerza interamericana". Uno de los propósitos declarados de dicha acción era "en un espíritu de imparcialidad democrática, colaborar en la restauración de condiciones normales en la República Dominicana" y en el establecimiento en ese país de una atmósfera conducente al "funcionamiento de instituciones democráticas." $\mathrm{Co}$ mo sea que la historia juzgue estos hechos, cabe mencionar que dentro de unos pocos meses, y aun con la presencia de la fuerza interamericana, la República Dominicana volvió a tener elecciones que condujeron a la restauración de un gobierno civil.

No fue hasta muchos años después que la OEA emprendería acciones nuevamente en una situación relativa a la gobernabilidad democrática. La OEA guardó silencio y se automarginó cuando las dictaduras primaban en la región entre mediados de 1960 y fines de la década de los setenta, lo que convenció a mucha gente que la organización era incapaz de respaldar con medidas efectivas su compromiso principista con la solidaridad democrática en las Áméricas. 
La situación cambió con.la crisis interna en Nicaragua, particularmente debido a la violación sistemática y masiva de los derechos humanos por el gobierno de Anastasio.Somoza. Así, se convocó una Reunión de Cancilleres en septiembre 1978. Aunque también existían problemas fronterizos entre Nicaragua y Costa Rica, la reunión tuvo un fuerte acento político debido a las preocupaciones internacionales sobre la democracia y los derechos humanos en Nicaragua. Como resultado; se formó una Comisión sobre Conciliación y Cooperación Amistosa que condujo negociaciones con el gobierno de Somoza en busca de una solución a la crisis. En una resolución que estableció los fundamentos para la solución definitiva al conflicto, e incluso con la participación del gobierno afectado, los ministros declararon en junio 1979 que la solución en Nicaragua debería basarse en:

"1. El reemplazo definitivo e inmediato del régimen de Somoza.

2. La instalación en el territorio nicaragüense de un gobierno democrático, cuya composición debía incluir los principales grupos representativos que se oponen al régimen de Somoza y que reflejan la libre voluntad del pueblo de Nicaragua.

3. La garantía del respeto a los derechos humanos de todos los nicaragüenses sin excepción.

4. Elecciones libres lo antes posible, que deberán conducir al establecimiento de un gobierno verdaderamente democrático. que garantice la paz, la libertad y la justicia".

El claro pronunciamiento de lạ OEA, además de flexibilizar -por decir lo menos- el concepto de no-intervención, reforzó el enfoque de la negociación colectiva en favor de la democracia y la paż en Centroamérica impulsada por un grupo de países regionales, cuya principal expresión fue el Acuerdo de Esquipulas, un importante precedente político y jurídico en lo que concierne al nexo entre, por un lado, la paz y la seguridad en la subregión centroamericana y, por otro, el ejercicio de la democracia y el respeto de los derechos humanos dentro de cada país en el área.

La firme posición de la OEA en Nicaragua aconteció en un contexto de afirmación de la conducta independiente en materia de política exterior por parte de muchos países latinoamericanos, en un clima de distensión Este-Oeste, y en un momento de renovada importancia de los derechos humanos en la política exterior de los Estados Unidos bajo la administración de Carter y de amplio rechazo 
internacional a las violaciones a los derechos humanos por parte del régimen de Somoza. Por otra parte, los Estados Unidos, así como muchos otros países, habían llegado a la conclusión de que se tenía que encontrar una alternativa -preferentemente moderada en la opinión de los Estados Unidos- a la dictadura de Somoza.

Durante la década de 1980, con el retorno a la democracia en la mayoría de los países latinoamericanos, el tema de la democracia volvió a ser, nuevamente, un punto focal del quehacer interamericano. Así, por ejemplo, la Asamblea General de la OEA de 1984, celebrada en Brasilia, expresó la voluntad de los Estados miembros de aunar esfuerzos para establecer las condiciones de bienestar y desarrollo conducentes a que los pueblos de las Américas tuvieran una vida de "libertad y dignidad". La misma asamblea convocó a una sesión especial de ese cuerpo para 1985, a objeto de examinar y, si correspondiese, adoptar proyectos de enmiendas a la Carta de la OEA.

La Asamblea General Especial celebradá en Cartagena de Indias, Colombia, en 1985, aprobó el Protocolo de Enmienda a la Carta de la OEA, otro hito en la evolución de la doctrina democrática en el sistema interamericano. En esa ocasión, se agregó la siguiente frase al Preámbulo a la Carta: "...la democracỉa representativa es condición indispensable para la estabilidad, la paz y è desarrollo de la región". Aún más importante, se añadió la siguiente frase en el Capítulo I relativo a los propósitos esenciales de la organización: "Promover y consolidar democracia representativa, dentro del respeto al principio de no-intervención".

El movimiento hacia la democracia en los países latinoamericanos elevó aun más la relevancia de la democracia en la OEA. Una resolución de la Asamblea General celebrada en Guatemala en 1986, declaró que, "por primera vez en muchas décadas, muchos Estados miembros tuvieron elecciones libres, con el resultado de que se han establecido sistemas democráticos, representativos y pluralistas de gobierno"; recordó que el propósito de la Organización es la promoción y consolidación de la democracia representativa, respetando el principio de la no-intervención, e instó, finalmente, a "los gobiernos de las Américas cuyas sociedades tienen problemas que requieren conciliación y unidad nacional para que emprendan o continúen un diálogo genuino" conducente a "mejorar la situación de los derechos 
humanos y a fortalecer el sistema democrático representativo y pluralista".

En este nuevo contexto, no constituyó sorpresa alguna cuando Argentina y Brasil firmaron varios importantes protocolos de acuerdo en 1986, que más tarde condujeron al esquema de integración MERCOSUR, que señalaban como un objetivo clave el propósito de "consolidar la democracia como una modalidad de vida y sistema de gobierno". Los presidentes de Argentina y Brasil declararon en esa oportunidad que un requisito previo básico para la participación de terceros países en el plan de integración sería su condición de países con gobiernos democráticos.

En contraste con Nicaragua, la acción de la OEA en Panamá en 1989 buscó una fórmula de consenso con el General Manuel Antonio Noriega que respetaría la voluntad soberana del pueblo panameño expresada en elecciones libres. Independientemente de otras consideraciones claves, el fracaso de la OEA en Panamá indicó la insuficiencia operacional y normativa del sistema interamericano para implementar los principios de la democracia representativa y la solidaridad democrática establecidos en la Carta. La reunión de la Asamblea General en Santiago, Chile, remedió esta insuficiencia cuando adoptó el Compromiso de Santiago, y el mecanismo de reacción contra los golpes de Estado, incorporado en la resolución sobre la defensa de la democracia representativa. Cabe hacer notar que los cambios ocurridos en Santiago estuvieron precedidos de una declaración firmada en mayo 1991 por los presidentes de Bolivia, Colombia, Ecuador, Perú y Venezuela con ocasión de la Quinta Reunión del Consejo Presidencial del Grupo Andino, donde se indicó la necesidad de "enmendar la Carta de la OEA para proveer, inter alia, la suspensión colectiva inmediata de relaciones diplomáticas con cualquier país miembro de la Organización en caso de la interrupción ilegal del sistema constitucional..." " Por último, uno de los pasos más recientes y significativos en el desarrollo de la doctrina interamericana sobre democracia fue la reforma de la Carta de la OEA -el Protocolo de Washington-aprobada en diciembre 1992 que, una vez que se ratifique, permitirá la suspensión de la Organización de aquellos Estados miembros donde sea derrocado, mediante el uso

\footnotetext{
${ }^{8}$ Ver Resolución No837 de la Asambjea General de la OEA de Guaternala, 1986.

9mActa de Caracas", V Consejo Presidencial Andino, Caracas, Venezuela, 18 mayo 1991, p. 12.
} 
de la fuerza, un gobierno elegido democráticamente. Esta importante reforma -originalmente propuesta por Argentina-fue acompañada también por modificaciones a la Carta que destacan la determinación de la Organización para enfrentar la pobreza como un obstáculo a la consolidación de la democracia.

\section{La OEA, la democracia y el concepto de soberanía: acciones recientes y algunas reflexiones.}

En años recientes, la OEA ha emprendido iniciativas importantes, tales como las descritas anteriormente, en la codificación de los abundantes precedentes para la acción hemisférica en favor de la democracia. Los casos de Haití, Perú y Guatemala, así como también las contribuciones recientes hechas por la OEA en la observación de procesos electorales en Nicaragua, El Salvador, Haití, Surinam, Paraguay y en otros países, son demostraciones concretas de los esfuerzos colectivos de la Organización concordantes con la doctrina americana de la solidaridad democrática.

Haití fue la primera prueba del nuevo instrumento para la acción colectiva para salvaguardar la democracia en las Américas. Cuando, el 30 de septiembre de 1991, las fuerzas militares de Haití expulsaron al Presidente Jean-Bertrand Aristide, se desató èl mecanismo creado sólo meses antes en Santiago. En un plazo de pocos días, los cancilleres se reunieron en Washington y resólvieron a reconocer al Presidente Aristide y sus representantes como el único gobierno legítimo de Haití, y recomendaron que todos los Estados miembros emprendiesen pasos específicos para aislar económica y diplomáticamente al grupo que había tomado el poder en Haití. Además, los cancilleres despacharon a Haití una misión especial compuesta de varios ministros y el Secretario General con un mandato de presionar para la restauración inmediata del gobierno elegido democráticamente.

Cuando esa misión fracasó en el logro de su objetivo, los ministros se reunieron nuevamente en Washington y endurecieron sus recomendaciones, llegando a recomendar el congelamiento inmediato de todos los activos del Estado de Haití retenidos en cualquier Estado miembro de la OEA. Además, se definieron los planes de cooperación para implementarse una vez restaurada la adminis- 
tración del Presidente Aristide y se avanzaron criterios sobre los medios para fortalecer la democracia constitucional en Haití.

En mayo de 1992, los cancilleres de la OEA adoptaron un paso adicional al recomendar a los Estados miembros, entre otras medidas, la negación de acceso a instalaciones portuarias a cualquier embarcación que infringiera el embargo; el monitoreo del cumplimiento del embargo; y la negación de visas a "perpetradores y defensores del golpe" en Haití. Sin embargo, al constatarse más adelante que el embargo comercial claramente estaba fracasando debido, particularmente, a violaciones por parte de países no-hemisféricos, los cancilleres instaron a todos los miembros de la OEA, así como también a las Naciones Unidas, para que implementaran cabalmente las medidas acordadas en las Reuniones $A d-H o c$ de Cancilleres.

Las presiones para endurecer el embargo por la vía del involucramiento activo de Naciones Unidas en la crisis de Haití se incrementaron, incluyendo una resolución de diciembre de 1992 acordada por los cancilleres del hemisferio que otorgó un mandato al Secretario General de la OEA "para explorar la posibilidad y conveniencia" de llevar la situación de Haití al Consejo de Seguridad de la ONU para obtener la aplicación universal del embargo comercial recomendado por la OEA. La designación por el Secretario General de la ONU de Dante Caputo, ex-Ministro de Relaciones Exteriores de Argentina, como enviado especial para Haití y, simultáneamente, como representante del Secretario General de la OEA, colocó la crisis de Haití en una nueva fase de negociaciones y presiones sobre el régimen de facto.

En consideración a que países fuera del hemisferio aún no adherían al embargo comercial, y por tanto lo hacían inoperativo, y tomando en cuenta que las negociaciones para una solución política a la crisis de Haití seguían bloqueadas por las autoridades de facto, el gobierno legítimo de Haití formalmente pidió, en junio 1993, la intervención del Consejo de Seguridad de las Naciones Unidas. En una resolución histórica (No841), el Consejo de Seguridad decidió, actuando bajo el Capítulo VII de la Carta de la ONU, imponer un embargo mundial de petróleo y prohibir embarques de armamentos a Haití, en tanto que también congeló los activos en el exterior controlados por el gobierno de facto.

A pesar de la referencia en la resolución 841 a una "situación excepcional y única" en el caso de Haití, y a la declaración hecha por el Presidente del Consejo de que la resolución en cuestión no 
constituía un precedente, el hecho es que dicha resolución fue la primera vez que una crisis política interna relacionada esencialmente con la recuperación de la democracia provocaba medidas tan drásticas por parte del Consejo de Seguridad de la ONU. Esta resolución puede interpretarse, por tanto, como un paso adicional en la acción colectiva en la defensa del "derecho a la democracia", esta vez incluyendo países fuera del hemisferio occidental pero en el apoyo de medidas adoptadas por los cancilleres de las Américas dentro de la OEA.

Las nuevas medidas en el marco del Consejo de Seguridad condujeron a una solución de compromiso para la restauración de la democracia, conocida como el "Acuerdo de la Isla de Gobernadores", entre el Presidente Aristide y las fuerzas militares. Posteriormente, un nuevo Primer Ministro, Robert Malval, designado por el Presidente Aristide asumió en Haití, y se levantaron las sanciones internacionales en anticipación del regreso del Presidente Aristide a Haití. Sin embargo, las fuerzas militares de Haití no cumplieron con los términos del acuerdo, tornándolo así inoperativo. En consecuencia, el Consejo de Seguridad de la ONU renovó las sanciones contra Haití-incluyendo un bloqueo naval de armas y embarques de petróleo-y la OEA, por su parte, volvió a recomendar amplias medidas de embargo en octubre de 1993.

Finalmente, luego de un período de empeoramiento de la situación humanitaria en Haití y de imposibilidad de hacer cumplir lo dispuesto en el Acuerdo de la Isla de Gobernadores, el Consejo de Seguridad de la ONU adoptó una importantísima resolución (No940, del 31 de julio de 1994) autorizando, con arreglo al capítulo VII de la Carta de la ONU, a los Estados miembros a "integrar una fuerza multinacional bajo mando y control unificados $y$, dentro de ese marco, a recurrir a todos los medios necesarios para facilitar la partida de Haití de los dirigentes militares, de conformidad con el "Acuerdo de la \sla de Gobernadores", el pronto regreso del presidente legítimamente electo y el restablecimiento de las autoridades legítimas del gobierno de Haitin". Junto con autorizar, de manera inédita, el uso de "todos los medios necesarios" para restaurar la legalidad democrắtica en Haití, el Consejo de Seguridad señaló el "carácter singular" de la situación haitiana lo que ameritaba una "reacción excepcional". Tal resolución fue aprobada sin oposición, pero con la abstención de Brasil y China. 
Como se sabe, pocas semanas:después, y bajo la amenaza de una invasión militar por parte de Estados Unidos y una coalición de países caribeños, el régimen de facto ien:Haití permitió el despliegue pacífico de las fuerzas militares: nofteamericanas en Haití, en el marco de un acuerdo negociado:por el ex-Presidente de Estados Unidos Jimmy Carter, cuyo objetivo era la implementación de los puntos esenciales del "Acuerdo de la Isla de Gobernadores". Posteriormente, a mediados de octubre de 1994, el Presidente Jean Bertrand Aristide volvió finalmente a Haití, reasumiendo el mando presidencial e iniciando una nueva etapa de la atribulada vida democrática de Haití.

Como conclusión, si se tiene presente la conducta tradicional de aceptación cómplice de golpes de Estado por parte de la OEA, la acción en relación a Haití por lo menos señaló un cambio hacia una inédita voluntad hemisférica y mundial de resistir a los enemigos de la democracia.

El mecanismo de Santiago se activó una segunda vez cuando, el 5 de abril de 1992, el Presidente Alberto Fujimori del Perú, quien fuera elegido democráticamente, cerró el Congreso ilegalmente; intervino el poder judicial; detuvo a varios diputados, líderes políticos y gremiales; y suspendió diversos derechos cívicos, incluyendo el de la libre expresión. Pocos días después de ấcontecidos tales hechos, los cancilleres americanos se reunieron y "deploraron profundamente" las acciones del Presidente Fujimori, instaron a la restauración de la democracia en Perú e instaron a las autoridades peruanas a que respetaran plenamente los derechos humanos. Al mismo tiempo, los ministros nombraron una misión diplomática especial que viajó al Perú para promover negociaciones entre las fuerzas de oposición y el gobierno para la restauración de la democracia.

Algunos países, incluyendo Estados Unidos, cortaron su ayuda económica al Perú. El Grupo de Río, mecanismo permanente para la consulta y coordinación entre los paísés latinoamericanos y caribeños, suspendió a Perú de sús reuniones. El Grupo de Río, fundado sobre una premisa de gobernabilidad democrática, ya había adoptado la práctica de suspender gobiernos de Estados miembros donde se interrumpiese ilegalmente la democracia. En este marco de antecedentes, la reunión de cancilleres de la OEA sobre Perú celebrada en Nassau, Bahamas, en mayo 1992, contó con la inexperada presencia del propio Presidente Fujimori quien, revirtiendo declaraciones an- 
teriores, se comprometió a la restauración democrática en su país mediante un proceso que culminaría en la elección de un Congreso Constitucional Democrático.

Las elecciones del Congreso Constitucional tuvieron lugar a fines de noviembre de 1992, bajo la observación electoral de la OEA, con la participación de sólo algunas fuerzas de oposición, ya que otras se marginaron alegando la carencia de garantías suficientes para elecciones justas y libres. Más tarde, se celebraron elecciones municipales, también con la supervisión electoral de la OEA. Claramente, las elecciones representaron un paso en la dirección de la restauración democrática, pero no aseguraron el pleno retorno a la democracia en Perú.

El 25 de mayo de 1993, cuando el entonces Presidente de Guatemala, Jorge Serrano, suspendió las garantías constitucionales en un virtual autogolpe, la comunidad hemisférica reaccionó rápida y enérgicamente basado en el mecanismo creado en Santiago mediante la resolución 1080. El mismo día de las acciones de Serrano, el Consejo Permanente se reunió y convocó una reunión de emergencia de cancilleres mientras, simultáneamente, el Secretario General de la OEA viajaba a Guatemala, acompañado por tres cancilleres de países regionales, en una misión investigadora destinada a advertir al Presidente Serrano y a las fuerzas armadas guatemaltecas acerca de las eventuales consecuencias internacionales de las acciones tomadas contra la democracia. A su vez, los presidentes centroamericanos se reunieron y enviaron un mensaje claro a las autoridades guatemaltecas para la revocación de las medidas antidemocráticas.

Unos pocos días después del autogolpe los cancilleres se reunieron en Washington, el 3 de junio. Pero, ese mismo día Serrano ya había dejado la Presidencia forzado por una ola de resistencia interna y de presión externa. Cuando los Ministros de la oEA se congregaron una vez más para considerar la situación de Guatemala, el 7 de junio, y después de una nueva visita a la nación centroamericana por parte del Secretario General de la OEA, la democracia constitucional había vuelto a Guatemala y el ex-Procurador General de la República para los Derechos Humanos, Ramiro de León Carpio, habido sido designado por el Congreso como el nuevo Presidente constitucional. La OEA, según el testimonio del nuevo presidente, había jugado un 
papel internacional clave en el apoyo a los esfuerzos internos para recobrar la democracia en Guatemala. ${ }^{10}$

Más allá del éxito en el caso de Guatemala; los magros resultados de las acciones de la Organización con respecto a Haití, y, en cierta medida, Rerú, se puede concluir que, para hacer operativa la premisa democrática de la Carta y las resoluciones de Santiago, quizás sea necesario que la OEA adopte instrumentos y procedimientos prácticos adicionales. Ciertamente, la OEA debería trabajar más estrechamente con Naciones Unidas, que tiene la experiencia y el mandato para aprobar y aplicar resoluciones obligatorias. Además, las reacciones de la organización hemisférica a derrocamientos de gobiernos democráticos podrían mejorarse mediante, por ejemplo, la formulación de estrategias comprensivas para enfrentar golpes de Estado; más diplomacia preventiva para anticiparse a amenazas inminentes a la democracia; y más actividades de fortalecimiento de las instituciones democráticas a través de la Unidad para la Promoción de Democracia de la OEA.

En todo caso, el considerable progreso alcanzado en el sistema interamericano con respecto a la acción colectiva en apoyo al derecho emergente a la democracia ha puesto en jaque las interpretaciones convencionales sobre el principio de no-intervención.

La evidencia presentada conduce a la conclusión de que, por lo menos en el hemisferio occidental, el concepto de soberanía ha evolucionado desde la autoridad jurisdiccional considerada como suprema, absoluta e ilimitada, hacia una autoridad igual a ta de todo otro Estado independiente pero limitada por el derecho internacional y fundada en la voluntad del pueblo del territorio pertinente. En consecuencia, las acciones de condena o presión a un gobierno que llega al poder mediante medios ajenos a la expresión libre de la soberanía popular no infringe el principio de la no-intervención, ya que este principio deriva su autoridad del derecho internacionalmente reconocido de que los pueblos deben decidir libremente su propio destino, un derecho que obviamente se infringe en su esencia cuando el poder de gobernar es arrebatado violentamente. Por ende, la intervención ilegal es aquella intervención que subvierte la soberanía

\footnotetext{
${ }^{10}$ Para una evaluación positiva del papel de la OEA en el caso de Guatemala ver Peter Hakim, "Behind Guatemala's Miracle", The Christian Science Monitor, 23 de junio, 1993; y el editorial "Back and Forth in Guatemala", The Washington Post, 12 de julio, 1993, p. A14.
} 
de un pueblo, pudiendo ella tener su origen tanto en fuentes externas como internas.

Por cierto, no todo acto emprendido por la comunidad internacional animado primordialmente por el deseo de defender un gobierno democrático es legítimo. La política de protección de las democracias debe tomar debida cuenta de las inquietudes sobre el abuso y los costos potenciales de las buenas intenciones. El mundo de la postguerra no está preparado para abrazar la afirmación irónica de Talleyrand de que "la no-intervención es una palabra política y metafísica que significa casi la misma cosa que intervención". La no-intervención es un principio de enorme importancia que permite que cada pueblo soberano tenga igual discreción en la formulación de sus propias políticas e instituciones públicas. Las asimetrías de poder entre los Estados no pueden traducirse; por tanto, en diferencias en la libertad de elegir. Por consiguiente, todo gobierno que refleja la voluntad soberana del pueblo retiene un margen bastante grande de discreción. Pero todos los gobiernos están, evidentemente, igualmente obligados a ejercer discreción política de manera de respetar los "otros" principios de las Cartas de las Naciones Unidas y de la OEA.

De hecho, existe un equilibrio entre la concepción tradicional de la soberanía y la visión más moderna sobre los límites de la discreción estatal en el Artículo 16 de la Carta de la OEA. Allí los Miembros afirman el "derecho [de cada Estado] a desenvolver libre y espontáneamente su vida cultural, política y económica", pero también sostienen que "en este libre desenvolvimiento, el Estado respetará los derechos de la persona humana y los principios de moral universal". La esencia de la materia fue bien definida por el diplomático y jurista uruguayo Héctor Gros Espiell cuando escribió que "el derecho soberano de cada Estado de organizarse libremente está limitado por los derechos de los seres humanos que siempre deben respetarse, con base en el principio de que el Estado está al servicio de los hombres y de la moral universal que impregna, da significado y otorga un fundamento a cualquier y todo orden jurídico". 11

Ahora bien, si los gobiernos latinoamericanos vacilan en autorizar la coerción externa en nombre de la democracia, su cautela no

\footnotetext{
${ }^{11}$ Héctor Gros Espiell, "Derechos Humanos: Etica, Derecho y Política", en: Jeannette Irigoin (ed.), Nuevas Dimensiones en la Protección del Individuo, (Santiago: Instituto de Estudios Internacionales, Universidad de Chile, 1991), p. 174.
} 
es inexplicable. Después de todo, durante las últimas cuatro décadas América Latina fue testigo de cómo, en el nombre de la democracia; las superpotencias muchas veces procuraban promover intereses estratégicos estrechos. Sólo el término de la Guerra Fría ha inducido a los gobiernos latinoamericanos a tener posiciones más proclives a actuar, a través de instituciones regionales y subregionales, junto a Estados Unidos, Canadá y los Estados anglófonos del Caribe, para defender y promover la democracia representativa.

La fuerza como un medio de expulsar un gobierno de facto es y probablemente continuará siendo inaceptable a un número considerable de gobiernos y entidades no-gubernamentales del hemisferio. El problema de quién ejercerá y controlará el uso de la fuerza en un contexto hemisférico asimétrico es una razón para tal actitud. El peligro de la aplicación selectiva debido a motivaciones de poder es claramente otra causa.

Dentro de la OEA tampoco existe un consenso, ni existe un mandato, para las operacionès armadas de mantención de la paz para ayudar a restaurar la democracia. Aun así, especialmente los Estados pequeños del Caribe tienen la legítima preocupación de que sus democracias sean amenazadas por grupos organizados de criminales armados y entrenados por elementos extranjeros, que intentasen. tomarse el poder por la fuerza en esos países. Una manera de reconciliar las dudas de varios países americanos sobre eventuales acciones militares para defender la democracia con las inquietudes de los países pequeños del Caribe podría ser un pacto entre Estados dispuestos a ayudarse mutuamente para garantizar la supervivencia de la democracia. Por supuesto, mientras más Estados participàn en tal tratado, menor será el peligro de intervención por motivos ulteriores.

En todo caso, en años recientes, la OEA se ha involucrado en algunas actividades que caen entre la mantención de la paz sin armas y el fomento de la democracia. Por ejemplo, desde su creación en 1990, la Comisión de Apoyo y Verificación (CIAV-OEA) ha estado fiscalizando el desarme y la reintegración social de los ex-contras en Nicaragua. Esta tarea, conjuntamente con la observación de las elecciones de 1990, le fueron solicitadas a la OEA bajo los términos del acuerdo de paz de Tela, Honduras, en agosto de 1989. La CIAV-OEA ha estado involucrada no solamente en el desarme, alimentación y protección de los ex-contras después de retornar a Nicaragua desde Honduras, sino también en la extensión de servicios 
humanitarios a los combatientes ex-sandinistas. En el esfuerzo de desmovilización la CIAV-OEA ha trabajado con alredédor de 30.000 contras y ha desarrollado planes adicionales, incluyendo un programa de autoayuda para la construcción de viviendas. Más importante aún, el personal internacional de la CIAV-OAS en Nicaragua ha jugado un reconocido papel clave de mediación entre la oposición armada y el gobierno nicaragüense.

La OEA ha desarrollado similares funciones en el caso de Suriname. Invitada por el gobierno de Suriname, la OEA se involucró en la formalización de un acuerdo para una paz duradera en el interior de ese país. Los dos objetivos específicos acordados entre el gobierno y la OEA fueron: 1) ayudar en el proceso de paz y 2) colaborar en la promoción y fortalecimiento de la democracia. Las negociaciones de $\mathrm{paz}_{\bar{\gamma}}$ apoyadas por la OEA, entre el gobierno y los grupos rebeldes culminaron exitosamente en agosto 1992, resultando en un proceso de desmovilización. Una misión de la OEA recibió y presenció la destrucción de armas y otros equipos militares. En 1993 el papel de la OEA en Suriname cambió hacia la asistencia al desarrollo, educación cívica $y_{3}$ en general, al fortalecimiento de las instituciones democráticas.

En suma, el concepto tradicional de soberanía ha ido cambiando en décadas recientes debido, entre otros aspectos, a la transformación de la solidaridad democrática de una prescripción moral a una obligación legal internacional. A través de su adhesión voluntaria a la Carta de Naciones Unidas y a los diversos tratados sobre derechos humanos, virtualmente todos los Estados se han comprometido a satisfacer normas internacionales en la materia y a aceptar el monitoreo internacional de su cumplimiento. Esto es aun más válido en el caso de los países del hemisferio occidental, que se encuentran comprometidos con la Carta de la OEA y con otros acuerdos normativos más exigentes en cuanto a democracia y derechos humanos.

\footnotetext{
${ }^{12}$ Sobre el trabajo de la Ciav-oza en Nicaragua, ver "OAs goes in Peace (That's What It Came For)", The New York Times, 16 julio 1992, p. A12; Santiago Murray, "Building Towards Reconciliation", Americas, Vol.44, N93, marzo-abril 1992, pp. 52-53. Ver también "Informe del Secretario General sobre los Trabajos y Programas de la CIAV-OEA en Nicaragua", CP/doc.2112/90 add. 2, Washington, D.C., 3 diciembre 1991.

${ }^{13}$ La primera reunión de la OEA en Suriname observó el desarme de facciones en conflicto y testimonio, en septiembre de 1991, las elecciones presidenciales en que el Dr. Ronald Venetiaan salio electo. Sobre el papel de la OEA en Suriname, ver "Report of the Secretary General on the O.AS. Activities in the Peace Process in the Republic of Suriname*, CP/doc.2335/93, Washington, D.C., 15 enero 1993.
} 
Un último desafío -menos visible- a la idea clásica de la soberanía emana de los cambios que han ocurrido en la economía mundial. La interdependencia ha aumentado enormemente, al igual que el grado de globalización de asuntos económicos. La nueva.revolución tecnológica ha alterado la propia naturaleza del proceso productivo, llegando a ser los aportes de conocimiento más importantes que el capital, el trabajo y los recursos naturales, llevando a algunos analistas a afirmar que en la nueva economía internacional compiten redes de empresas en base a capacidades y conocimientos que combinan para crear valor, y que, a futuro, ya no existirán economías nacionales propiamente tales. Por otra parte, han surgido diversas zonas económicas ampliadas a través de acuerdos de libre comercio o de procesos integradores más profundos como el de la actual Unión Europea.

Ciertamente, en estos úlitimos casos hay una renuncia yoluntaria de soberanía. Pero, en otras situaciones dicha reducción es inevitable. La revolución tecnológica en marcha demuestra que "las propias fronteras nacionales ya no están bajo un control soberano genuino". En relación a los mercados financieros, por ejemplo, las fronteras nacionales son de poca importancia. De hecho, las fronteras son cada vez más porosas en áreas de gran significancia soberana como la transmisión de dinero, ideas e información. Hoy en día, las dictaduras ya no pueden controlar lo que sus ciudadanos ven o escuchan. Además, cuando los dictadores reprimen violentamente a su propio pueblo, las comunicaciones instantáneas permiten que esto sea conocido inmediatamente por todo el mundo.

Problemas tales como el tráfico de drogas y la degradación del medio ambiente también plantean desafíos a los enfoques tradicionales de la soberanía nacional. Aunque los países de América Latina no abandonarán, por ejemplo, su legítimo derecho a explotar sus recursos naturales, para realizar dicha explotación de una manera sustentable han aceptado la necesidad de cooperar internacionalmente en lo que dice relación al desarrollo sustentable, reconociendo así que este es un tema que trasciende las fronteras nacionales.

En suma, los nuevos tiempos desafían la soberanía convencional como nunca antes. El mundo de la interdependencia y la globa:lización económica así como también el ascenso de un virtual

\footnotetext{
${ }^{14}$ George P. Shultz, "On Sovereignty", discurso presentado en la ocasión del 25 Aniversario de la National Academy of Engineering, Wasinington, D.C., 4 octubre 1989, p. 4.
} 
"derecho a la democracia" son retos a la no-intervención concebida como un "muro de contención". contra otros principios fundamentales, tales como el ejercicio de democracia representativa y el respeto a los derechos humanos.

La comunidad internacional enfrenta una de las interrogantes más fundamentales de la relaciones exteriores en la era de post-Guerra Fría; una tensión entre, por un lado, la noción clásica de soberanía y, otro, los intereses humanitarios. Tradicionalmente, la soberanía ha tomado precedencia sobre cualquier otra consideración, pero-como un alto funcionario de la ONU ha observado-esta postura tradicional "es un tema de examen cada vez más acucioso en la legalidad y la moralidad internacional contemporáneas". 15

Por lo menos en el derecho internacional americano, la teoría y la práctica se inclinan hacia el reconocimiento de un derecho a la democracia, basado tanto en fundamentos morales como en sólidas normas jurídicas.

\section{Nota final.}

La defensa y la promoción colectiva de la democracia representativa, sea por medio de las obligaciones contenidas en la Carta de la OEA, o de declaraciones, resoluciones y acciones de la organización, es un tema de larga data en el sistema interamericano y, de hecho, se ha intensificado en años recientes. Puede concluirse, entonces, que existe una arraigada doctrina sobre la democracia representativa en el sistema interamericano que, acompañada por importantes precedentes de acción, apoyan la noción de que en las Américas se debería defender la democracia colectivamente. Los pasos avanzados en el hemisferio al respecto en años recientes subrayan, por lo tanto, el argumento central de este ensayo, de que se está consolidando un "derecho a la democracia" en el sistema interamericano.

En un contexto mundial nuevo, caracterizado por el fin de la polarización que acompañó la Guerra Fría y por una profundización de la interdependencia global económica y tecnológica, la aceptación creciente en el derecho internacional americano de la acción colectiva pacífica para implementar el derecho a la democracia, evidente-

\footnotetext{
${ }^{15}$ Giandomenico Picco, citado en "Defining the New Sovereignty", Parliamentarians for Global Action, Ne4, diciembre 1991, p. 4.
} 
mente ha presentado un desafío a la vieja interpretación de la soberanía. Como conseeuencia, en la realidad actual hay un número limitado de asuntos que un Estado puede reivindicar legítimamente como dentro de su exclusiva jurisdicción doméstica.

No obstante, aunque, en efecto, existe un papel muy trascendente para la comunidad internacional en el fomento y la protección de la democracia, se debe recordar que la democracia en: cualquier país en último término descansa en las manos de su pueblo y depende de la existencia de una sociedad civil que pueda hacer uso efectivo de los instrumentos que esa democracia provee. La consolidación de la democracia es un reto de largo plazo y es dudoso que pueda ocurrir por la imposición externa. Además, una tarea tan difícil debe incluir incentivos y medidas positivas para enfrentar los problemas socioeconómicos, especialmente la pobreza crítica, que en los países en desarrollo son una amenaza a la democracia tan seria como los golpes de Estado. Es necesario enfrentar la dictadura de la miseria y la pobreza, así como también la dictadura política.

Pero, pese a las dificultades inherentes en la promoción y defensa de la democracia, ya no puede haber duda alguna de que se ha desarrollado una doctrina hemisférica sólida sobre la democracia y que, en un momento cuando la idea democrática ha ganado legitimidad a través del mundo, es esencial buscar una convergencia entre doctrina y práctica tanto en la OEA como en otras organizaciones regionales. En el último término, el sistema interamericano será juzgado de manera principal por su capacidad y compromiso efectivo para actuar en conformidad con su doctrina de la promoción y defensa de democracia, dando así significado concreto al derecho a la democracia en las Américas. 